Gut, 1980, 21, 965-969

\title{
Treatment of alcohol-related liver disease with (+)-cyanidanol-3: a randomised double-blind trial
}

\author{
J C COLMAN, MARSHA Y MORGAN, ${ }^{*}$ P J SCHEUER, AND SHEILA SHERLOCK
}

From the Departments of Medicine and Histopathology, The Royal Free Hospital, London

SUMmARY A randomised double-blind trial of (+)-cyanidanol-3 (Catechin), $2 \mathrm{~g}$ /day versus placebo, was carried out in 40 patients with pre-cirrhotic alcohol-related liver disease over a three month period. Twenty received the active drug and 20 placebo; one non-compliant patient in the treatment group was withdrawn. Forty-one per cent (16/39) abstained from alcohol and showed significant improvements $(\mathbf{P}<0.005)$ in mean values for serum aspartate transaminase, serum gamma glutamyl transpeptidase, and mean corpuscular volume. Ten of the 16 showed overall histological improvement on liver biopsy. Fifty-nine per cent (23/39) continued to drink, though significantly reducing their mean daily alcohol intake $(P<0.001)$. No significant changes occurred in this group in mean serum enzyme values, though the mean value for mean corpuscular volume improved significantly $(P<0.01)$ and 16 of the 23 showed overall histological improvement. Changes occurred irrespective of treatment with Catechin which suggests that, over a three month period, this drug did not influence the course of alcohol-related liver disease.

The major factor in the pathogenesis of alcoholrelated liver injury is the direct toxic effect of ethanol or its metabolites on the liver cell. ${ }^{12}$ Oxidation of ethanol in the alcoholic is associated with a number of metabolic changes within the liver, including an increased nicotinamide adenine dinucleotide reduced form: nicotinamide adenine dinucleotide (NADH:NAD) ratio, ${ }^{3}$ decreased adenosine triphosphate (ATP) levels, ${ }^{4}$ and abnormal fragility of cell lysosomes. ${ }^{5}(+)$-Cyanidanol-3 (Catechin) is a bioflavonoid whose pharmacology is not completely clear $;{ }^{6}{ }^{7}$ nevertheless, it has been shown to normalise the NADH:NAD ratio, to increase ATP levels, and stabilise lysosomal membranes in the livers of rats with alcohol-induced liver injury ${ }^{8-11}$ It has also been shown to have a beneficial effect on collagen synthesis in rats given lathyrogenic drugs which would alter their collagen cross-linkage. ${ }^{1213}$ On theoretical grounds, therefore, Catechin could be of potential benefit in alcohol-related liver disease in humans.

We report the results of a prospective doubleblind randomised trial of Catechin versus placebo in

*Address for correspondence and requests for reprints: Dr M Y Morgan, Medical Unit, Royal Free Hospital, Pond Street, Hampstead, London NW3 2QG

Received for publication 17 June 1980
40 patients with pre-cirrhotic, hence potentially reversible, alcohol-related liver disease.

\section{Methods}

PATIENTS

The study group comprised 40 patients (26 male, 14 female) who had consumed alcohol in excess of $80 \mathrm{~g}$ daily for three or more years and in whom the liver biopsy showed pre-cirrhotic and hence potentially reversible alcohol-related liver disease. For the purpose of this study a pre-cirrhotic liver lesion was defined as any combination of fatty infiltration, alcoholic hepatitis, or fibrosis without nodule formation. All patients had been abusing alcohol up to the start of the trial. Informed consent was obtained from all the patients. All but essential medications-for example, antihypertensive agents -were discontinued; vitamin supplements were not routinely prescribed.

An initial inpatient assessment was made of the drinking history, the physical condition, and of various haemotological and biochemical measures. Particular note was made of the serum aspartate transaminase (AST), serum gamma glutamyl transpeptidase $(\gamma$ GTP), and mean corpuscular volume (MCV). Liver biopsies were examined blindly by one of us (PJS) looking for centrizonal and portal 
Table 1 Details of sex, age, drinking histories, biochemistry, and haemotology of 39 alcoholics completing Catechin trial

\begin{tabular}{|c|c|c|c|c|c|c|c|}
\hline \multirow[t]{2}{*}{ Treatment $(n)$} & \multirow[t]{2}{*}{$\begin{array}{l}\text { Sex ratio } \\
M: F\end{array}$} & $\begin{array}{l}\text { Age } \\
(y r)\end{array}$ & $\begin{array}{l}\text { Drinking history } \\
(y r)\end{array}$ & $\begin{array}{l}\text { Alcohol intake } \\
(\mathrm{g} / \mathrm{kg} / \text { day })\end{array}$ & $\begin{array}{l}A S T \\
(I U / l) \\
\left(r r^{*} 3-17\right)\end{array}$ & $\begin{array}{l}\gamma G T P \\
(I U / l) \\
(r r-7-48)\end{array}$ & $\begin{array}{l}M C V \\
(f) \\
(r r<80-95)\end{array}$ \\
\hline & & \multicolumn{6}{|c|}{$M e a n \pm I S D$} \\
\hline $\begin{array}{l}\text { Catechin (19) } \\
\text { Placebo (20) }\end{array}$ & $\begin{array}{l}11: 8 \\
14: 6\end{array}$ & $\begin{array}{l}48 \cdot 2 \pm 9 \cdot 0 \\
48 \cdot 8 \pm 9 \cdot 9\end{array}$ & $\begin{array}{l}17 \cdot 0 \pm 9 \cdot 8 \\
20 \cdot 2 \pm 12 \cdot 5\end{array}$ & $\begin{array}{l}3 \cdot 16 \pm 2 \cdot 2 \\
3 \cdot 59 \pm 1 \cdot 8\end{array}$ & $\begin{array}{l}40 \cdot 4 \pm 22 \cdot 4 \\
30 \cdot 1 \pm 16 \cdot 8\end{array}$ & $\begin{array}{l}329 \cdot 8 \pm 237 \cdot 9 \\
236 \cdot 6 \pm 277 \cdot 1\end{array}$ & $\begin{array}{l}101 \cdot 1 \pm 11 \cdot 5 \\
101 \cdot 0 \pm 7 \cdot 0\end{array}$ \\
\hline
\end{tabular}

*rr: reference range for control population.

inflammation, fatty infiltration, Mallory bodies, centrizonal liver cell damage, central and portal fibrosis, siderosis, and cholestasis. Each feature was graded as $0=$ absent, $1=$ mild, $2=$ moderate, or $3=$ severe.

The 40 patients were then randomly assigned to two equal groups of 20 . The treated group received $2 \mathrm{~g}$ Catechin daily in four divided doses for 12 weeks, while the control group were given an identically presented placebo for a similar time.

After discharge from hospital, patients were reviewed at two, four, six, and eight weeks. At each visit an assessment of alcohol intake was made as accurately as possible from the patient's own reports, reports from family and work contacts, and by random blood ethanol estimations. Physical examination and laboratory tests were repeated and a careful note made of any side-effects. At 12 weeks patients were readmitted to hospital for full reassessment including liver biopsy. The second liver biopsy was examined in exactly the same way as the first. An overall assessment of improvement or deterioration in histological features was then made by re-examining the two biopsies as a pair and comparing the numerical scores. This was done without knowledge of the patient's drinking be- haviour or drug treatment in the three months between biopsies.

For purposes of analysis, the patients were initially divided into two groups on the basis of whether they had been abstinent from alcohol or not during the three months trial. Patients consuming alcohol in any quantity were regarded as continuing to drink even if they had significantly reduced their intake.

The effects of treatment with Catechin were assessed by comparing results in the placebo and Catechin-treated patients in the abstinent and drinking groups. Data were analysed using Student's $t$, $2 \times 2 \chi^{2}$, and Fisher's exact probability tests.

Approval was obtained from the Committee on Safety of Medicines for an initial trial of this drug in alcohol-related liver disease not to exceed three months' duration. Approval was also obtained from the hospital's Ethics Committee.

\section{Results}

One non-compliant male patient was withdrawn from the trial. Thirty-nine patients completed the trial, 19 in the treated group and 20 in the control group. Table 1 gives details of the patients on admission; control and treatment groups were fairly homogeneous.

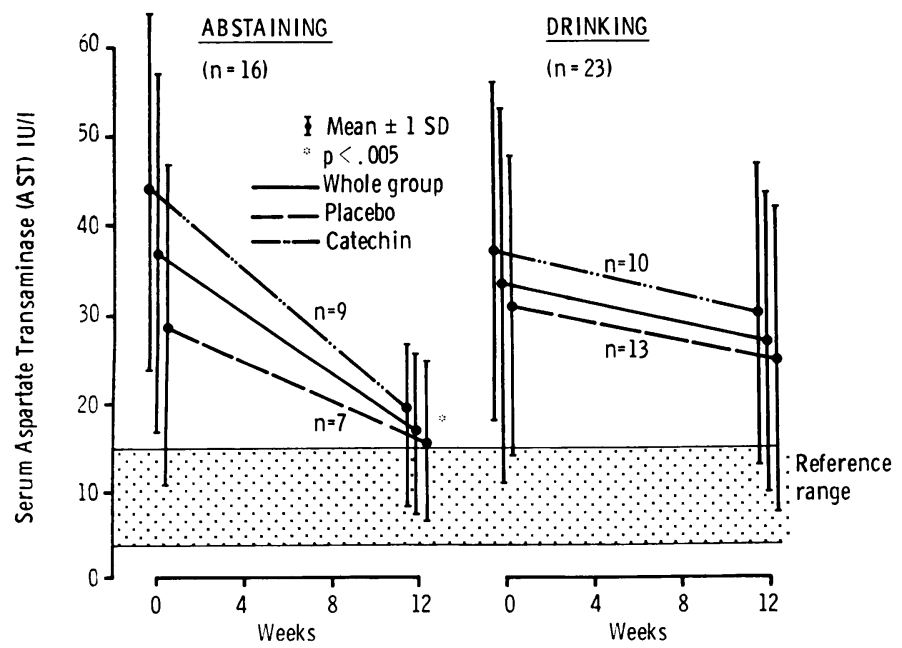

Fig. 1 Changes occurring in mean $A S T$ values over the trial period in relation to alcohol intake and treatment with Catechin or placebo. 


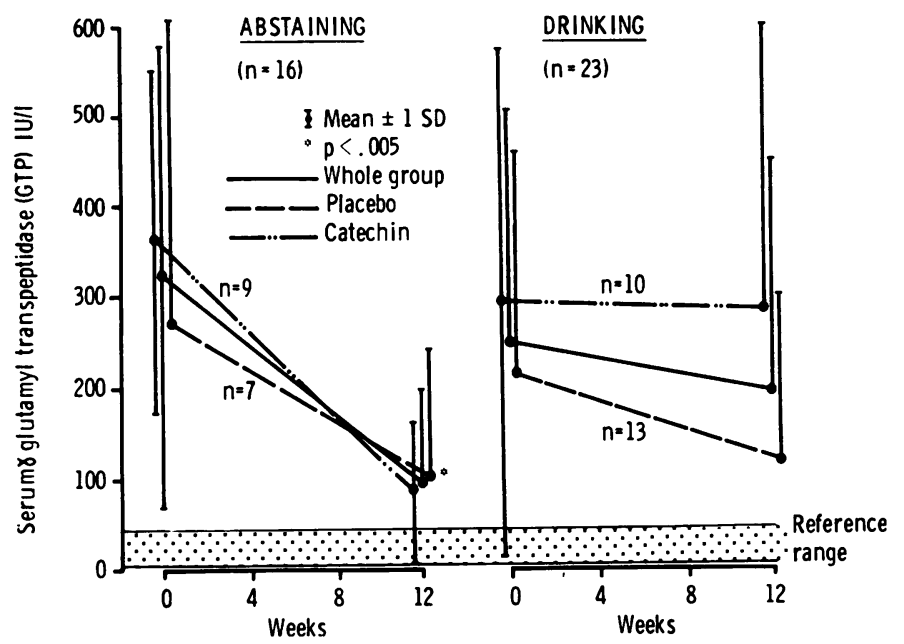

Fig. 2 Changes occurring in mean $\gamma$ GTP values over the trial period in relation to alcohol intake and treatment with Catechin or placebo.

Forty-one per cent of patients (16/39) abstained from alcohol and showed significant improvements $(\mathrm{P}<0.005)$ in mean AST $(36.8 \pm 20.4$ (ISD) to $17.0 \pm 8.9 \mathrm{IU} / \mathrm{l}), \quad \gamma \mathrm{GTP} \quad(326 \pm 262$ to $96 \pm 107$ $\mathrm{IU} / \mathrm{l})$, and $\mathrm{MCV}(103 \pm 10$ to $93 \pm 5 \mathrm{fl})$. Ten of these 16 patients showed overall histological improvement on liver biopsy.

Fifty-nine per cent of patients (23/39) continued to drink, though reducing their mean daily alcohol significantly from $3.52 \pm 2.2$ to $1.2 \pm 0.8 \mathrm{~g} / \mathrm{kg}$ body weight $(\mathrm{P}<0.001)$. No significant changes were seen in mean AST or $\gamma$ GTP values, but the mean MCV improved significantly from $100 \pm 8.0$ to $95 \pm 5.0 \mathrm{fl}$ $(\mathrm{P}<0.01)$. Sixteen of these 23 patients showed overall histological improvement.

Changes occurring in mean AST, rGTP, and MCV during the trial in relation to alcohol intake and treatment with active drug and placebo are shown in Figs. 1-3. Changes occurred irrespective of treatment with the active drug and were related to the changes in drinking habit.

The effects of changes in drinking habit on liver

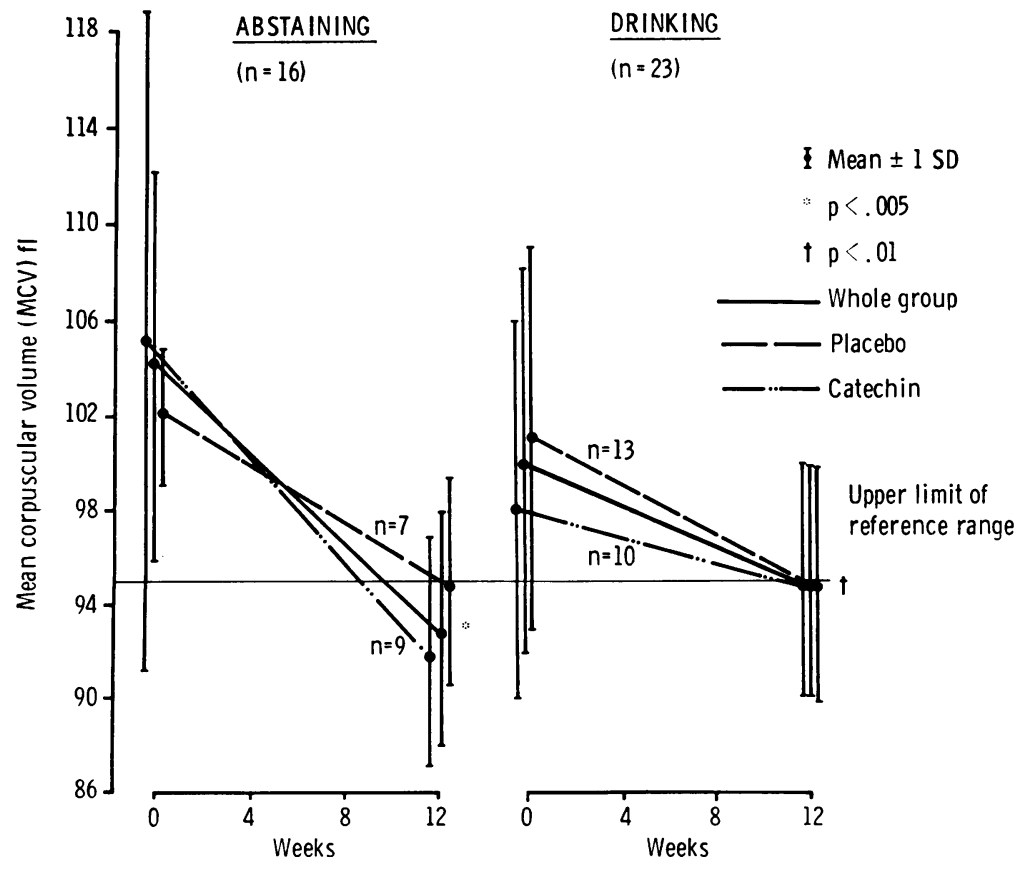

Fig. 3 Changes occurring in mean $M C V$ values over the trial period in relation to alcohol intake and treatment with Catechin or placebo. 
Table 2 Overall histological change in 39 alcoholics during treatment with catechin or placebo over three month period in relation to their drinking habits

\begin{tabular}{|c|c|c|c|c|c|c|}
\hline \multirow{3}{*}{$\begin{array}{l}\text { Treatment group } \\
(n)\end{array}$} & \multicolumn{6}{|c|}{ Overall histological assessment } \\
\hline & \multirow{2}{*}{\multicolumn{2}{|c|}{$\frac{\text { Deteriorated }}{(\text { no. })(\%)}$}} & \multicolumn{2}{|c|}{ Unchanged } & \multicolumn{2}{|c|}{ Improved } \\
\hline & & & (no.) & $(\%)$ & (no.) & $(\%)$ \\
\hline \multicolumn{7}{|l|}{ Abstinent } \\
\hline Whole group (16) & 2 & 12.5 & 4 & $25 \cdot 0$ & 10 & 62.5 \\
\hline Catechin (9) & 2 & 22.0 & 2 & 22.0 & 5 & 56.0 \\
\hline Placebo (7) & & - & 2 & $29 \cdot 0$ & 5 & $71 \cdot 0$ \\
\hline \multicolumn{7}{|l|}{ Drinking } \\
\hline Whole group (23) & & - & 7 & $30 \cdot 5$ & 16 & $69 \cdot 5$ \\
\hline Catechin (10) & & - & 3 & $30 \cdot 0$ & 7 & $70 \cdot 0$ \\
\hline Placebo (13) & & - & 4 & $31 \cdot 0$ & 9 & $69 \cdot 0$ \\
\hline
\end{tabular}

histology were less clear cut than the changes in biochemical and haematological measures, with overall histological improvement observed in $62.5 \%$ of patients who abstained (10/16) and in $69.5 \%$ who continued to drink (16/23), (Table 2). The pattern of histological improvement was similar in both groups. Treatment with active drug or placebo had no appreciable effect on liver histology.

The drug was well tolerated in doses of $2 \mathrm{~g}$ daily. One female patient on the active drug developed a high swinging temperature for which no cause was found but which settled spontaneously within three days without discontinuing the drug. No other side-effects were observed.

\section{Discussion}

On theoretical grounds Catechin should benefit patients with alcohol-related liver disease. Ethanol oxidation is associated with a number of metabolic changes as a net result of which an excess of reducing equivalents, primarily NADH, is generated. ${ }^{3}$ This increases the NADH:NAD ratio and results in alterations in lipogenesis and lipid oxidation which favour hepatic triglyceride accumulation..$^{16-21}$ Indirectly, the activity of the citric acid cycle is depressed resulting in a decrease in ATP levels. ${ }^{4}$ Catechin has been shown to simultaneously increase ATP and normalise the NADH:NAD ratio in animals with experimentally induced steatosis. ${ }^{1011}$ Additionally, acute ethanol intoxication causes an abnormal fragility of cell lysosomes which results in release of lysosomal enzymes into the serum, ${ }^{5}$ and Catechin has the capacity to stabilise lysosomes. ${ }^{89}$ However, within the framework of this trial, Catechin did not confer any benefit on patients with alcohol-related liver disease. Improvements seen in these patients could be related entirely to their reduced alcohol intake.

Significant biochemical improvements were seen in the patients in this study who abstained from alcohol but not in the patients who continued to drink even in reduced amounts. Similar findings were reported by Galizzi et al. ${ }^{14}$ These workers measured AST in 14 alcoholics with histologically proven minimal liver damage and found raised values in $64 \%(9 / 14)$. Six patients abstained from alcohol and when assessed a mean of 33 days later showed significant improvement in their mean AST value. The remaining eight patients, however, continued to drink and, when assessed a mean of 118 days later, showed no significant change in mean AST value. Measurement of the AST is thus useful for monitoring alcohol abuse. Similar remarks may be made about $\gamma$ GTP.

The mean MCV values improved significantly in the patients who abstained but also in those who continued to drink. This is in keeping with the findings of Morgan et al. ${ }^{15}$ who reported that, while the MCV is a useful diagnostic guide to alcohol abuse, its value as a monitor for continuing abuse, at least in the short-term, is strictly limited.

Histological improvement occurred in similar percentages of the patients who abstained or continued to drink. However, the changes were monitored over a relatively short time period and biopsy findings after a longer period may well have differentiated the two groups. Nevertheless, the histological improvement in the patients in whom it occurred was striking and reflects the tremendous capacity of the liver to withstand alcohol poisoning and to return to normal function when the toxin load is reduced.

The biochemical and histological improvements seen in patients with alcohol-related liver disease who significantly reduce their alcohol intake is so pronounced that any additional effect conferred by Catechin might escape attention. Thus, it is possible that long-term trials might reveal beneficial effects on collagen biosynthesis ${ }^{1213}$ not apparent in shortterm trials.

(+)-Cyanidanol-3 (Catechin) and placebo were kindly supplied by Dr T B Pulvertaft, of Zyma Pharmaceuticals Ltd, Macclesfield, Cheshire.

\section{References}

${ }^{1}$ Lieber CS, Rubin E. Alcoholic fatty liver in man on a high protein and low fat diet. Am J Med 1968; 44: 200-6.

${ }^{2}$ Rubin E, Lieber CS. Alcohol-induced hepatic injury in non-alcoholic volunteers. $N$ Engl J Med 1968; 278: 869-76.

${ }^{3}$ Lieber CS. Liver adaptation and injury in alcoholism. N Engl J Med 1973; 288: 356-62. 
${ }^{4}$ Lieber CS. Alcohol and the liver. In: Bittar EE, ed. The biological basis of medicine Vol 5. London: Academic Press, 1965: 317-44.

${ }^{5}$ Geokas MC, Rinderknecht $\mathrm{H}$. Plasma arylsulfatase and $\beta$-glucuronidase in acute alcoholism. Clin Chim Acta 1973; 46: 27-33.

${ }^{6}$ Bohm K. Die Flavonoide. Cantor: Aulendorf, 1967.

${ }^{7}$ Das MP, Sothy SP. Studies on flavonoid metabolism. Biochem J 1971; 125: 417-23.

${ }^{8}$ Cetta G, Gezzeli G, Quartieri A, Castellani A. Protective effect of flavonoids on collagen or lathyritic rats. Experientia 1971; 27: 1046-8.

${ }^{9}$ Caneghem P. Influence of some hydrosoluble substances with vitamin $\mathrm{P}$ activity on the fragility of lysosomes in vitro. Biochem Pharmacol 1972; 21 : 1543-8.

${ }^{10}$ Gajdos A, Gajdos-Torok M, Horn R. Augmentation du taux hepatique de l'ATP chez le rat blanc par administration de (+)-catechine. $C R$ Soc Biol 1969; 163: 2089-91.

${ }^{11}$ Gajdos A, Gajdos-Torok M, Horn R. The effect of $(+)$-catechin on hepatic level of ATP and the lipid content of liver during experimental steatosis. Biochem Pharmacol 1972; 21 : 594-600.

${ }^{12}$ Blumenkrantz N, Asboe-Hansen G. IRCS medical science: biochemistry, connective tissue, skin and bone $1975 ; 3:$ 573-5.

${ }^{13}$ Cetta G, Fossati G, Castellani AA. In vivo and in vitro evidence for the action of $(+)$-catechin and its derivatives on connective tissue. In: Bertelli A, ed. New trends in the therapy of liver diseases. Basle: Karger, 1974: 140-9.
${ }^{14}$ Galizzi J, Morgan MY, Chitronukroh A, Sherlock S. The detection of minimal alcoholic liver disease by three methods. Scand J Gastroent 1978; 13: 827-31.

${ }^{15}$ Morgan MY, Camilo ME, Luck W, Sherlock S, Hoffbrand AV. Macrocytosis in alcohol-related liver disease: its value for screening. J Lab Clin Haem 1980 (In press).

${ }^{16}$ Nikkila EA, Ojala K. Role of hepatic L- $\alpha$-glycerophosphate and triglyceride synthesis in production of fatty liver by ethanol. Proc Soc Exp Biol Med 1963; 113: 814-7.

${ }^{17}$ Lieber CS, Schmid R. The effect of ethanol on fatty acid metabolism: stimulation of hepatic fatty acid synthesis in vitro. J Clin Invest 1961 ; 40: 394-9.

${ }^{18}$ Lieber CS, Spritz N, De Carli LM. Fatty liver produced by dietary deficiencies: its pathogenesis and potentiation by ethanol. $J$ Lipid Res 1969 ; 10: 283-7.

${ }^{19}$ Lieber CS, Spritz N. Effects of prolonged ethanol intake in man: role of dietary, adipose and endogenously synthesized fatty acids in the pathogenesis of the alcoholic fatty liver. J Clin Invest 1966; 45: 1400-11.

${ }^{20}$ Lieber CS, Spritz N, De Carli LM. Role of dietary, adipose and endogenously synthesized fatty acids in the pathogenesis of the alcoholic fatty liver. $J$ Clin Invest 1966; 45: 51-62.

${ }^{21}$ Mendenhall CL. Origin of hepatic triglyceride fatty acids: quantitative estimation of the relative contributions of linoleic acid by diet and adipose tissue in normal and ethanol fed rats. J Lipid Res 1972; 13: 177-83. 